\title{
Exploring Contemporary Issues in Sustainable Energy
}

\section{Dr. Paul Gannon, Montana State University}

Associate Professor, Chemical Engineering

Dr. Ryan Anderson, Montana State University

Mr. Justin W Spengler, Montana State University

Dr. Carolyn Plumb, Montana State University

Carolyn Plumb is the Director of Educational Innovation and Strategic Projects in the College of Engineering at Montana State University (MSU). Plumb has been involved in engineering education and program evaluation for over 25 years. At MSU, she works on various curriculum and instruction projects including instructional development for faculty and graduate students. She also serves as the college's assessment and evaluation expert. 


\section{Exploring Contemporary Issues in Sustainable Energy}

\section{Abstract:}

The overall aim of this research is to promote engineering graduate success in complex, interdisciplinary environments relevant to sustainability. In this study, two unique engineering courses were compared in terms of individual student responses to multiple-choice questions before and after in-class online research, in addition to active discussions. The two courses, both focused on "sustainable energy," were a 90-student $1^{\text {st }}$ year science-core course with primarily non-science majors, and a 33-student $4^{\text {th }}$ year technical elective course with primarily seniorlevel engineering majors. The in-class online research and discussions were structured in a manner to focus on five issues (science/engineering, environmental, social, economic, and political) related to hydraulic fractured oil/gas well stimulation, or "fracking." This topic was chosen as a contemporary societal issue with significant engineering considerations. Eight (8) multiple-choice questions were aimed at identifying students' understanding of basic science and engineering concepts, as well as gauging opinions on the practices and policies related to fracking. Following initial questions, students were presented basic fracking science, engineering, impacts and policy information in video format. Students, pre-assembled into equal-sized groups, then conducted individual online research focusing on the specific issue to which their group was assigned. Student scribes were self-identified within the groups to compile and distill information collected during online research, which they subsequently shared in open discussion. Students were then asked identical questions following the discussion, in addition to rating the effectiveness of the class format on their individual learning. In general, students' basic understanding of fracking improved significantly, their opinions on the topic shifted from neutrality, and the majority agreed that the format was effective in their learning. Additional results from comparing the two courses, as well as examples of student-generated materials are presented and discussed in context of the overall research aim.

\section{Introduction:}

Engineering students face increasingly complex problems whose solutions_often require interdisciplinary teams and significant interaction with diverse stakeholders [1-6]. Exploring contemporary issues in society within engineering classrooms may help prepare students for these challenges. One contemporary issue with significant engineering considerations is the advancement and proliferation of hydraulic fractured oil/gas well stimulation, or "fracking" [7]. Fracking has substantially increased oil and gas production in existing reservoirs and has enabled exploration and production of otherwise inaccessible oil/gas resources. Fracking has also received negative attention from its environmental impacts including land surface and geological disruption, water use, and pollution. Engineers involved with fracking, or other complex problems, may benefit from analysis of multiple/conflicting perspectives on these problems. 
This study used both quantitative and qualitative data collection to assess perspectives and opinions of two distinct undergraduate student cohorts on a contemporary issue (fracking) before and after an engaging in-class learning activity. Results and analyses from the study will be used to inform future activities and advance the overall research aim. The two distinct student cohorts came from two existing courses, both focused on "sustainable energy." One is a $1^{\text {st }}$-year,

science-core course with 90 primarily non-STEM majors, and the other is a $4^{\text {th }}$-year technical elective course with 33 engineering majors. The $1^{\text {st }}$-year course has no pre-requisites, and thus has students from almost every major and at every level in the university; the bulk of this student cohort are $1^{\text {st }}$ and $2^{\text {nd }}$ year students from non-STEM majors. The $4^{\text {th }}$-year course has prerequisites of engineering thermodynamics and materials science, thus limiting this student cohort to upper-level engineering majors. This study follows a similar format employed during these same classes in the previous year. In that year, the topic was the Keystone XL pipeline, which at the time was also a topic of societal importance with strong ties to engineering. While the approach to that facilitated discussion was more 'casual', it seemed the students benefited from the approach. With that motivation, an updated delivery approach was implemented based on perceived lessons from the previous year. This paper explains the delivery approach for the topic of fracking in the two courses, discusses the results, and comments on potential changes in the courses in context of advancing the research aim.

\section{Methods:}

Our approach relies on students being able to conduct online research during class using appropriate sources. Therefore, preceding the activity day, students received formal instruction from a university librarian regarding online research methods and sources, and were encouraged to bring a portable electronic device to the next class (personal or library-loaned). Upon arrival on the day of the activity, students were divided into five equal-sized groups positioned around the classroom. Students then candidly responded to a series of eight multiple-choice questions (Table 1) before being presented two short (5 minutes) online instructional videos on fracking; one from industry [8], another from a science-education advocacy organization [9]. The five groups were then each assigned unique issues related to fracking on which to focus their in-class online research:

1. Science/Engineering - innovations, safe guards, monitoring and materials;

2. Environmental - local, regional and global ecosystems;

3. Social - individuals, communities, regions/nations;

4. Economic - local, regional and global economies; and,

5. Political - government, regulations/policies and elected officials.

Students were then encouraged to collaborate within their groups, research their issue online individually, and consolidate their findings in written format. Following the research period, students presented and discussed their findings in a structured, open dialogue. To facilitate that discussion, each group identified a scribe who would take notes on the 
major/common findings of the group. These 'nuggets' of information within each topic were uploaded to the course website. After the discussion, students again responded to the same series of questions. Anonymous student responses were recorded via i-clickers (large class) or bubblesheets (smaller class).

Table 1. Questions posed to students before and after the activity.

\begin{tabular}{|c|c|}
\hline Question & Response Options \\
\hline 1) I Understand What Fracking Is........................ & $\begin{array}{l}\text { A }=\text { Strongly Agree } \\
B=\text { Agree Somewhat } \\
C=\text { Not Really } \\
D=\text { No }\end{array}$ \\
\hline $\begin{array}{l}\text { 2) Fracking is a Topic of Local* Discussion (*where I'm } \\
\text { from }) \ldots \ldots \ldots \ldots \ldots \ldots \ldots \ldots \ldots \ldots \ldots \ldots \ldots \ldots \ldots \ldots \ldots \ldots \ldots \ldots \ldots \ldots \ldots\end{array}$ & $\begin{array}{l}\mathrm{A}=\mathrm{A} \text { major issue }, \text { discussed extensively } \\
\mathrm{B}=\mathrm{A} \text { minor issue, discussed but not extensively } \\
\mathrm{C}=\text { Not an issue at all } \\
\mathrm{D}=\text { Don't know }\end{array}$ \\
\hline 3) I Support or Oppose Fracking......................... & $\begin{array}{l}\text { A }=\text { Strongly Support } \\
\text { B }=\text { Support } \\
\text { C }=\text { Neutral } / \text { Don't Know } \\
\text { D }=\text { Oppose } \\
\text { E }=\text { Strongly Oppose }\end{array}$ \\
\hline 4) I am from an Area with Fracking....................... & $\begin{array}{l}A=\text { Yes } \\
B=\text { No } \\
C=\text { Don't Know }\end{array}$ \\
\hline 5) Which of These Factors is Most Important to Fracking & $\begin{array}{l}\mathrm{A}=\text { Societal } \\
\mathrm{B}=\text { Political } \\
\mathrm{C}=\text { Economical } \\
\mathrm{D}=\text { Environmental } \\
\mathrm{E}=\text { Technological }\end{array}$ \\
\hline 6) Which of These Factors is Least Important to Fracking & $\begin{array}{l}\mathrm{A}=\text { Societal } \\
\mathrm{B}=\text { Political } \\
\mathrm{C}=\text { Economical } \\
\mathrm{D}=\text { Environmental } \\
\mathrm{E}=\text { Technological }\end{array}$ \\
\hline $\begin{array}{l}\text { 7) Who Should Have the Most Authority in Decisions } \\
\text { Regarding Fracking Regulations....................... }\end{array}$ & $\begin{array}{l}\mathrm{A}=\text { Federal Government } \\
\mathrm{B}=\text { State Government } \\
\mathrm{C}=\text { Local Government } \\
\mathrm{D}=\text { Land Owners } \\
\mathrm{E}=\text { Don't Know }\end{array}$ \\
\hline 8) This Format Was Effective in My Learning............. & $\begin{array}{l}\text { A }=\text { Strongly Agree } \\
B=\text { Agree Somewhat } \\
C=\text { Neutral } \\
D=\text { Disagree Somewhat } \\
\text { E }=\text { Strongly Disagree }\end{array}$ \\
\hline
\end{tabular}

To facilitate these activities, three instructors were involved; the course instructor, the teaching assistant, and a faculty volunteer. As students investigated the topics and discussed within their assigned group, the instructors walked around the room to promote individual research and discussion. At times, this took on a 'devil's advocate' approach, and at other times, it was simply pointing the students in a new direction if needed. At minimum, it helped keep the 
students on task for the most part. The course instructor, in addition to initially walking around the room, overviewed the responses as they were entered into course website. With this information, the course instructor could guide the open dialogue, and encourage group participation as needed.

Results and Discussion:

The results presented below focus on several aspects of the approach: (1) the student responses to the questions posed; (2) the utility of this approach as observed by the instructors; and, (3) areas of improvement, in terms of delivery and quantifying success. Table 2 presents all results from anonymous student responses to the eight multiple-choice questions (Table 1) before and following the in-class activity. Summarized below are results from four of these questions, along with selected written comments from student groups.

Table 2. Raw Data (Student Responses to Table 1 Questions):

\begin{tabular}{|c|c|c|c|c|c|c|c|c|c|c|c|c|c|c|c|c|}
\hline \multicolumn{17}{|c|}{ 1st-Year Course } \\
\hline & \multicolumn{8}{|c|}{ Questions Preceding Activity } & \multicolumn{8}{|c|}{ Questions Following Activity } \\
\hline Responses & 1 & 2 & 3 & 4 & 5 & 6 & 7 & 8 & 1 & 2 & 3 & 4 & 5 & 6 & 7 & 8 \\
\hline A & 13 & 14 & 2 & 16 & 5 & 21 & 16 & 15 & 66 & 31 & 4 & 25 & 4 & 19 & 25 & 26 \\
\hline $\mathrm{B}$ & 46 & 34 & 14 & 46 & 2 & 31 & 21 & 20 & 23 & 37 & 17 & 50 & 1 & 42 & 29 & 36 \\
\hline $\mathrm{C}$ & 19 & 25 & 46 & 27 & 8 & 12 & 21 & 18 & 0 & 19 & 30 & 12 & 7 & 9 & 25 & 18 \\
\hline $\mathrm{D}$ & 12 & 15 & 21 & 0 & 73 & 3 & 18 & 19 & 0 & 3 & 31 & 0 & 74 & 1 & 9 & 7 \\
\hline $\mathrm{E}$ & 0 & 0 & 7 & 0 & 2 & 23 & 14 & 16 & 0 & 0 & 8 & 0 & 4 & 17 & 2 & 2 \\
\hline \multicolumn{17}{|c|}{ 4th-Year Course } \\
\hline & \multicolumn{8}{|c|}{ Questions Preceding Activity } & \multicolumn{8}{|c|}{ Questions Following Activity } \\
\hline Responses & 1 & 2 & 3 & 4 & 5 & 6 & 7 & 8 & 1 & 2 & 3 & 4 & 5 & 6 & 7 & 8 \\
\hline A & 5 & 3 & 2 & 4 & 0 & 11 & 6 & 8 & 24 & 5 & 3 & 7 & 1 & 7 & 8 & 12 \\
\hline B & 17 & 11 & 4 & 20 & 1 & 21 & 10 & 6 & 8 & 18 & 10 & 22 & 2 & 18 & 14 & 16 \\
\hline C & 9 & 16 & 19 & 9 & 7 & 0 & 7 & 7 & 1 & 11 & 8 & 5 & 4 & 5 & 8 & 3 \\
\hline D & 1 & 4 & 6 & 1 & 25 & 0 & 1 & 7 & 1 & 0 & 10 & 0 & 23 & 1 & 2 & 3 \\
\hline $\mathrm{E}$ & 1 & 0 & 3 & 0 & 1 & 2 & 10 & 6 & 0 & 0 & 3 & 0 & 4 & 2 & 2 & 0 \\
\hline
\end{tabular}

Figure 1 presents data from three questions before and after the activity, the $1^{\text {st }}$-year course on the left and $4^{\text {th }}$-year course on the right. From the first question (Figure 1 top), students' self-described understanding of fracking increased significantly following the activity. In the $1^{\text {st }}$-year course, it appears the self-described "fracking ignorance” was essentially eliminated by the activity. The remaining fracking ignorance in the $4^{\text {th }}$-year course $(2$ students, or 6\%) may be an entry error, or perhaps these students found the activity to be ineffective in improving their understanding. The second question (Figure 1 middle) reveals a significant shift from neutrality of students' support for or opposition to fracking following the activity. While students in both courses began largely neutral (51 and 56\%), neutrality decreased substantially following the activity (33 and 24\%). Following the activity, the $1^{\text {st }}$-year course students shifted more toward opposition to fracking and the $4^{\text {th }}$-year students were equally split in support of and opposition to fracking. The reason for this difference is unclear, but perhaps reflects differences in cohort predispositions. The $4^{\text {th }}$-year students may exercise more critical thinking, or may have pre-professional experiences to draw from. The $1^{\text {st }}$-year students are predominately non-STEM majors, and perhaps more influenced by the abundance and accessibility of opposition literature. Regardless, the activity appears to be effective in facilitating students' opinion formation, while they gain factual knowledge. The third question in Figure 1 (bottom) reports student opinions on 
authority over fracking regulations before and after the activity. Students appear to agree that government, at some level, should have this authority. The state-level was the most frequently selected for both classes before and following the activity. This preference may (in-part) arise from the prevalence of fracking within the state.

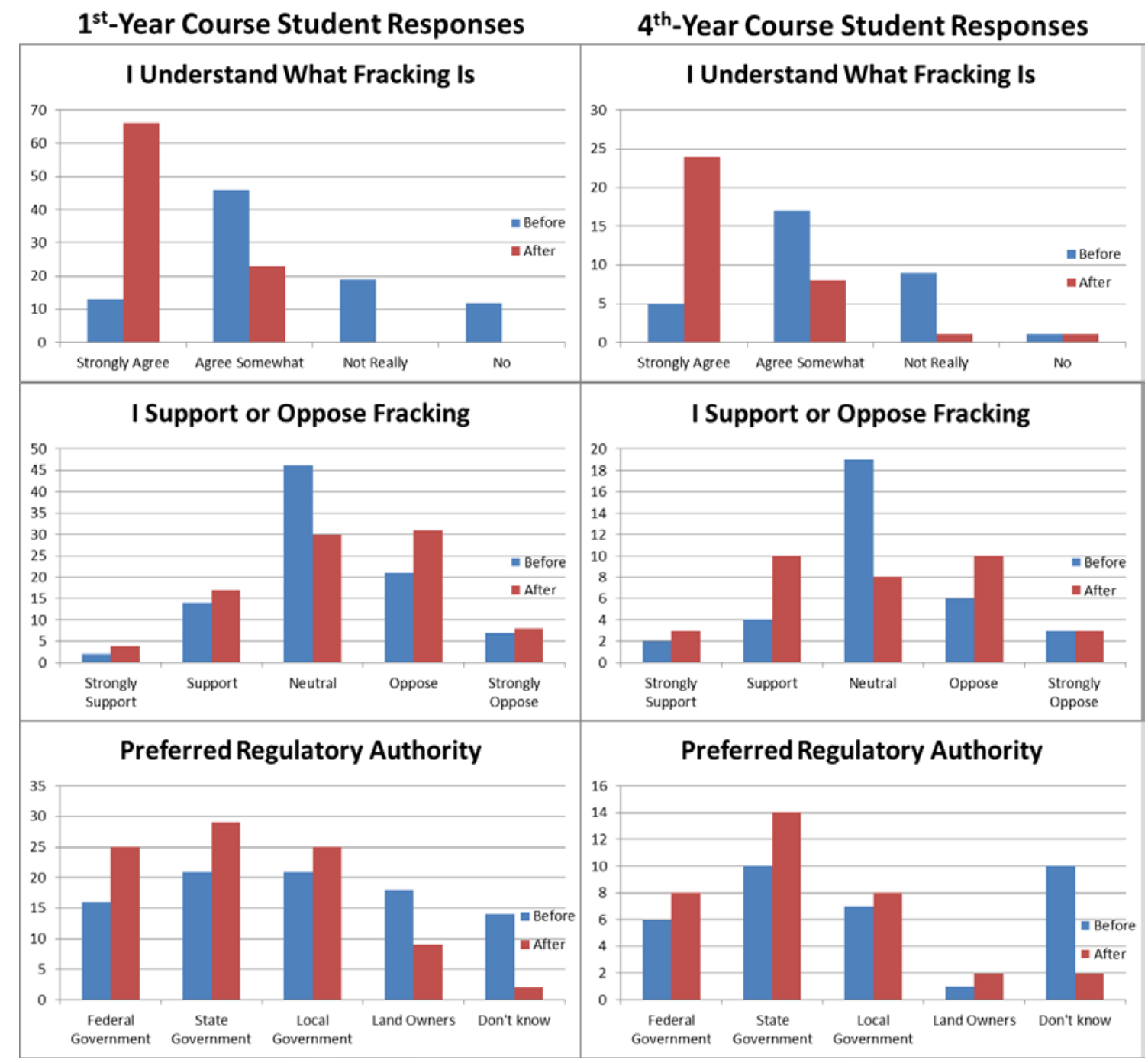

Figure 1. Results from multiple choice questions before and after in-class research activity.

Much of the course activity was focused on inter-group and intra-group discussions of student research findings. Student scribes within each group recorded some of this discussion; below are brief analyses and selected comments from each course and group:

1. science/engineering: groups in both courses seemed to focus on fluid used in fracking operations. The $1^{\text {st }}$-year group reported more on the disclosure of chemicals used in fracking, using terms such as "mystery water," "secrets of fracking fluids" and "green fracking." Some students seemed interested in understanding the mechanisms of the fracking fluid, whereas many others focused on the potential environmental impacts of its 
constituents. The $4^{\text {th }}$-year group reported more on the chemistry and physics of the fluids, and alternatives, using terms such as "fracking recipe," "waterless fracking methods" and "monitoring water quality." Most students seemed intrigued by new and existing technologies, and focused on improvements to minimize environmental impacts.

2. environmental: groups from different courses varied substantially in their reported findings. The $1^{\text {st }}$-year students within this group had the most numerous recorded discussions, focusing on a wide range of environmental impacts. Impacts were reported from fracking on earthquakes and land damage, to water pollution and its effects on the biosphere, in addition to climate change from resource consumption and fugitive emissions, as well as legacy effects of abandoned wells. Terms such as "dead fish," "polluted waters" and "earthquakes" were used frequently. The $4^{\text {th }}$-year students within this group recorded discussions of surface water use rate and contamination and the fate of abandoned wells, but did not go into near the detail as did the $1^{\text {st }}$-year students.

3. social: groups from both courses reported somewhat-similar findings, with some differences. The $1^{\text {st }}$-year group reported impacts on individuals (alleged health impacts from fracking contamination) as well as the impacts on global oil and gas trade (increasing exports, lowering imports). The $4^{\text {th }}$-year students reported on both potential positive (economic growth) and negative (water contamination) consequences of fracking for local communities.

4. economic: groups from both courses reported mostly-similar findings. The impacts (positive and negative) on local economies were the main foci, with effects on international trade and individuals reported to a lesser extent.

5. political: groups from both courses reported on the local, regional and international implications of fracking on political systems. The $1^{\text {st }}$-year students within this group had numerous recorded findings on the abundance of donations to political campaigns from fracking industries, as well as the evolving regulatory infrastructure surrounding fracking. They also focused on states that have bans on fracking operations. The $4^{\text {th }}$-year students within this group reported on jobs associated with fracking, and the political influence thereof, in addition to the national energy security that domestic fracking promotes.

Inter- and intra-group discussions were lively and for the most-part productive, with excited students wanting to share their personal and group's findings with other students. Numerous similarities in the discussions among the $1^{\text {st }}$ and $4^{\text {th }}$ year courses were noticed; however, discussions among the $1^{\text {st }}$ year students seemed more subjective and impassioned, relative to discussions among the $4^{\text {th }}$ year students, which seemed more objective and sober. This difference may be attributed (in-part) to the advanced cognitive development of the $4^{\text {th }}$ year student cohort, relative to the $1^{\text {st }}$ year student cohort [11]. 
Near the conclusion of the class, students were asked to rate the effectiveness of the class format on their learning. These data are presented in Figure 2, with the $1^{\text {st }}$ year students on the left and the $4^{\text {th }}$ year students on the right. Both groups of students appear to agree the class format was effective; however, this was not compared with their opinions on more traditional class formats, and specific reasons why the class format was effective were not solicited.

$1^{\text {st }}$-Year Course Student Responses

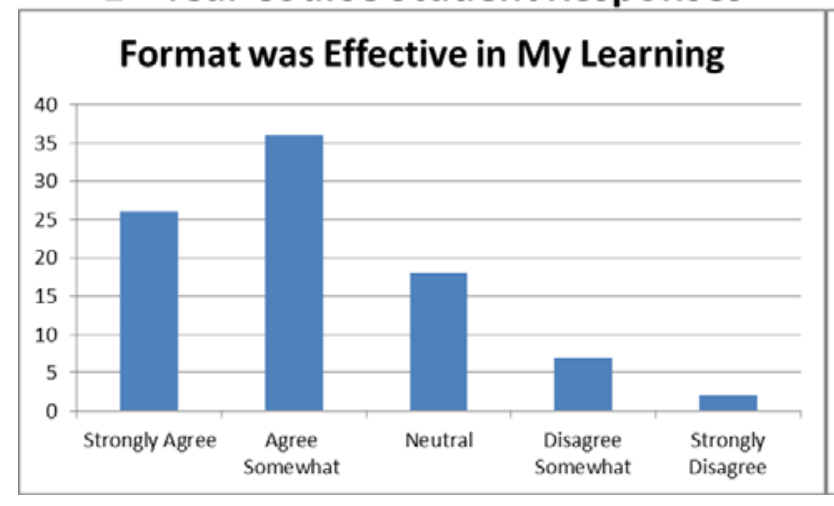

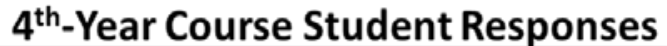

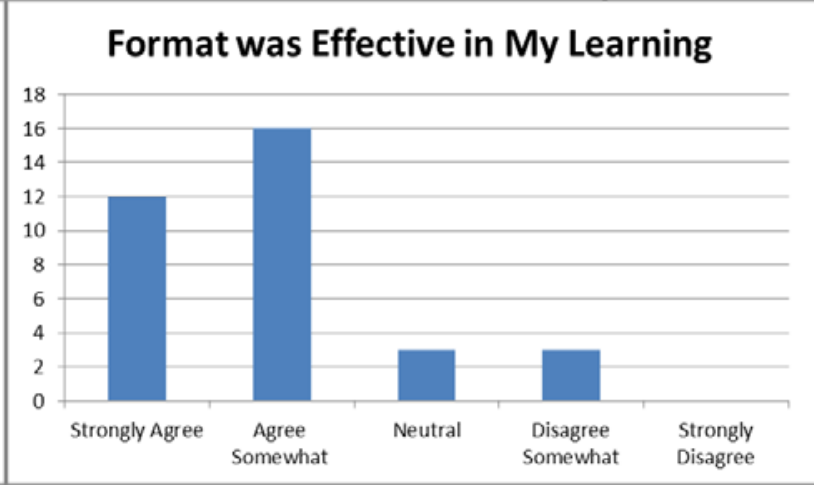

Figure 2. Results following in-class activity.

The efficacy of active learning within engineering education is well-established [10]. Active learning was leveraged in this study through students conducting guided independent and collaborative online research within class, coupled with open discussion of their findings. Students reported improved topical understanding and that they found the class format to be effective. Additionally, the format was effective in reducing reported neutrality on a contemporary issue with significant engineering implications. A significant amount of neutrality (33 and 24\%) was also maintained, suggesting students were thinking critically while gaining factual knowledge on a contemporary issue. Faculty-facilitated discussions appeared effective in student engagement, and many students reported continued topical engagement following class. These data are encouraging in regard to continuing to explore contemporary issues using a similar class format.

Many areas for improvement were identified through this preliminary study; some of them are summarized here. First, the question formatting, presentation and student response technologies need to be professionally developed to avoid inherent biases and promote honest, accurate responses. Additional questions, perhaps asked throughout the course term and beyond, could be designed to help gauge success toward research aims; promoting engineering student recruitment and preparing better engineering graduates. Second, the organization and interaction of groups could be better facilitated by the instructors to encourage focused dialogue, inclusion, and documentation of student contributions. To encourage student engagement and effectiveness of the activity, the generation of student-lead position papers on the topic, e.g., to be shared with public officials, could be explored. Finally, comprehensive literature reviews and rigorous research on existing pedagogies to promote engineering student recruitment and graduate success 
are necessary to maximize impact of future activities. Direct collaboration with education professionals on the structure, delivery and assessment of these activities will also encourage alignment with the overall research aims and effectiveness in transferability of key findings.

\section{Conclusions:}

Two unique cohorts of students within $1^{\text {st }}$ and $4^{\text {th }}$ year "sustainable energy" courses were compared in their responses to an active learning exercise focused on contemporary issues related to fracking. In analyzing results, three basic conclusions were drawn:

- Students' self-described understanding of fracking improved significantly;

- Student opinions on supporting or opposing fracking shifted from neutrality; and,

- Students reported that the class format was effective in their learning.

Results were encouraging in regard to continuing to explore contemporary issues in engineering classrooms using similar formats as a means to promote engineering student recruitment and graduate success in addressing complex problems. Collaboration with education professionals to improve delivery and assessment is ongoing, and processes to promote transferability of research findings are under development.

\section{References:}

1. American Society for Mechanical Engineering web site, accessed May 6, 2014: "Washington Policy Report May 2013.”

2. FEDERAL SCIENCE, TECHNOLOGY, ENGINEERING, AND MATHEMATICS (STEM) EDUCATION 5-YEAR STR ATEGIC PLAN, A Report from the Committee on STEM Education National Science and Technology Council, May 2013

3. National Academy of Engineering (2014), Making a World of Difference, National Academies Press.

4. National Academy of Engineering, Grand Challenges for Engineering, www.engineeringchallenges.org, updated 9/2013.

5. Johnson, Steven (2012). Future Perfect. New York: Penguin Press.

6. National Academy of Engineering (2005). Educating the Engineer of 2020. National Academies Press.

7. ASEE PRISM Features, “Get Fracking” - Thomas K. Grose, September 2011

8. “Animation of Hydraulic Fracturing (fracking)" - Marathon Oil: https://www.youtube.com/watch?v=VY34PQUiwOQ Accessed October 2014

9. "Facts About Fracking" - SciShow: https://www.youtube.com/watch?v=51wOisfdIPo\&list=PL73C8A01C82C423CB Accessed October 2014

10. M. Prince, Does Active Learning Work? A Review of the Research, Journal of Engineering Education, Volume 93, Issue 3, pages 223-231, July 2004

11. Perry, W. G., Jr. 1970. Forms of intellectual and ethical development in the college years: A Scheme. New York: Holt, Rinehart \& Winston. 